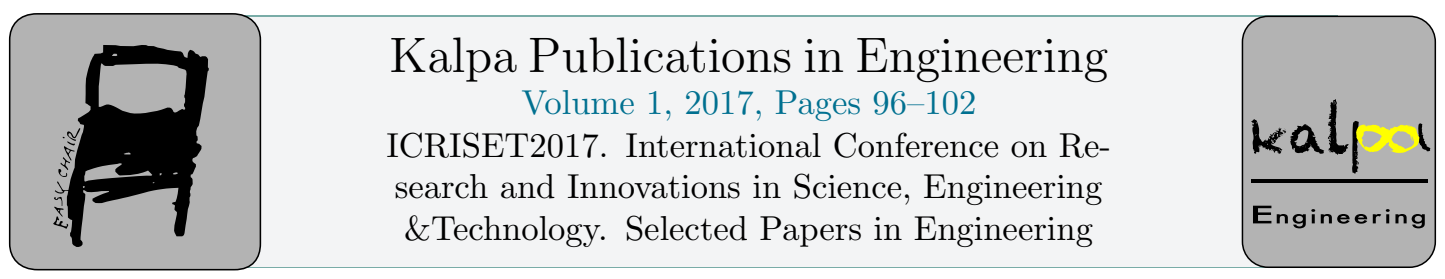

\title{
Parametric Study and Geometrical Optimization of Centrifugal Blower
}

\author{
V.H.Chaudhari ${ }^{1,4}$, Varun Parmar ${ }^{2,4}$, M.J.Zinzuvadia ${ }^{3,4,}$ \\ ${ }^{1}$ Assistant Prof., ${ }^{2}$ M.E.Student, ${ }^{3}$ Associate Prof. \\ ${ }^{4}$ Mech. Engg. Dept., BVM Engineering College, V.V.Nagar, Gujarat, India \\ Emails : vhchaudhary@bvmengineering.ac.in,mjzbvm@gmail.com
}

\begin{abstract}
Blower is used to deliver the air or gas with an appreciable rise in pressure against the flow resistance. It plays an important role in various industries for air-conditioning systems, furnaces and dust or fume extraction systems. The backward inclined blade centrifugal blower was considered for study and analysis. The parameters affecting performance were determined and important parameters were selected. For centrifugal blower, both impeller and casing parameters are considered for CFD analysis in ANSYS, where model was prepared in Creo2.0 parametric and CFD results were validated with the help of experimental results. For CFD analysis of models k- $\varepsilon$ turbulence model was used. Then range of parameters was used for doing DoE by Taguchi's method and detailed study of given blower was carried out. Models given by DoE were analyzed to get their performance and optimal model was found out which has $23.07 \%$ higher performance than current centrifugal blower.
\end{abstract}

\section{Introduction}

Blower uses for the continuous flow of air or gas that industrial blower generate, including combustion, ventilation, aeration, particulate transport, exhaust, cooling, air-cleaning, and drying as per applications. The industries served include electrical power production, pollution control, metal manufacturing and processing, cement production, mining, petrochemical, food processing, cryogenics, and clean rooms. Tahsin Engin et al. [1] investigates three-Dimensional fluid flow field in centrifugal flow fan and it was concluded that an impeller with backward-curved blades (type B) was very sensitive with variation of tip clearance; while the other two types radial tipped blades impeller (type C) and fully radial tipped blades impeller (type D)were not so sensitive. Radial tipped blades impeller (type C) presented a weak dependence on tip clearance variation. W.K. Ng et al. [2] had described computational fluid flow analysis, inside industrial ventilation fans, to facilitate computational design to achieve optimal fan performance characteristics eventually. There were some differences in values of gauge total pressure at outlet and total efficiency due to difference in setup and measurement 
between experimental results and numerical simulated results. Total efficiency of single inlet fan flow simulation results were close to experimental result. O.P.Singh et al. [3] investigated an effect of geometry parameters on centrifugal fan with forward and backward curved blade impeller. With increased in number of blade in forward curved blade, they found that flow coefficient, pressure and efficiency increase as compared to backward curved blade. As outlet angle increases, recirculation increases and obtain more discharge for given impeller speed of forward curved blades. Power consumption may me little bit higher but performance better as compared to backward curved blade [12]. Li Chunxi et al. [4] did analysis for the influence of enlargement of impeller on centrifugal fan. Comparison between original impeller and two modified impeller with increased the impeller outlet diameter with $5 \%$ and $10 \%$ respectively. They investigated experimental results of total pressure, flow rate, shaft power and sound power level increased, efficiency decreased with operation of larger impeller size fan. Chen-Kang Huang et al. [5] numerically simulated backward curved blade impeller of centrifugal blower and compared with given experimental data. He had made conclusion based on effect of blade angle, blade number, tongue length and scroll contour numerically and found the optimised model exhibited a better value of cost and performance [13, 14]. K.Vasudeva Karanth et al. [6] investigated effect of radial gap between impeller and diffuser on performance. They concluded that radial gap provides better energy conversion in impeller and enhanced energy transformation by diffuser with respect to optimum radial gap. They found overall efficiency increased with larger radial gap and also less pressure fluctuation at exit end of centrifugal fan. Mojtaba gholamian et al. [7] investigated effectiveness of inlet nozzle geometry on performance of fan used for HVAC system. The numerical analysis and experimental results show that by increasing of inlet diffuser diameter, continuously efficiency will increase. N. Vibhakar et al. [8] investigated to enhance overall performance of centrifugal blower with increasing number of blades. Numerical simulation and experimental results shows increament on flow coefficient with increment of number of blades because flow passage available between blades are very less which reduces turbulence and vortex flow $[13,14$, 16]. Yogesh Pathak et al. [9] and Atre Pranav et al. [10] carried out CFD analysis for single stage centrifugal blower to find effect of flow coefficient on performance, using k-E turbulence model and unstructured grid. They had concluded that pressure coefficient decreased with increase in flow coefficient and also static and total pressure increased with decrease in flow coefficient and velocity increased with increase in flow coefficient. The improvement of performance of centrifugal blower possible by increasing of impeller outlet diameter, reducing impeller wheel width with reduction of thickness of blade and increasing impeller inlet diameter [11,13,14]. Change in volute geometry parameters like radial distance between impeller and volute and tongue geometry had significant effect on performance of industrial centrifugal blower [5, 15]. C. N. Jayapragasan et al. [17] investigated performance by increasing speed and fillet radius at the inlet of blower with volute casing geometry and number of blades dimensions had kept constant. Results obtained from investigation shows that overall efficiency and discharge increases with increment of speed and fillet radius. It is equally true for axial flow fan [17].

\section{Solution Methodology}

For understanding performance on centrifugal blower using numerical analysis method, required data of blower available from Energy Process Equipment, Ahmedabad. The experimental data used for analysis is directly taken from manufacturer as shown in Table.1.

\begin{tabular}{ll|l|ll}
\hline Material & MS (Mode:EP36001) & & Material & MS (Mode:EP36001) \\
\cline { 1 - 1 } $\begin{array}{ll}\text { Impeller Type } \\
\text { No. of Blades }\end{array}$ & Backward inclined blade & Inlet diameter & $295 \mathrm{~mm}$ (Circular) \\
Outlet section & $300 \times 200 \mathrm{~mm}^{2}$
\end{tabular}




\begin{tabular}{|c|c|c|c|}
\hline & & & (Rectangular) \\
\hline Total Head & $22.785 \mathrm{~m}$ of air & Impeller speed & $880 \mathrm{rpm}$ \\
\hline Impeller o/d & $710 \mathrm{~mm}$ & Nature of medium & Atmospheric air \\
\hline Impeller i/d & $140 \mathrm{~mm}$ & Temperature & $25^{\circ} \mathrm{C}$ \\
\hline $\begin{array}{l}\text { Blade Inlet } \\
\text { Angle }\end{array}$ & $40^{\circ}$ & Density of air & $1.185 \mathrm{~kg} / \mathrm{m}^{3}$ \\
\hline $\begin{array}{l}\text { Blade Outlet } \\
\text { Angle }\end{array}$ & $76^{\circ}$ & Atm. pressure & $101325 \mathrm{~Pa}$ \\
\hline
\end{tabular}

Centrifugal blower model was prepared in the ANSYS 14.0 Workbench with 255148 nodes and 1154571 tetrahedral elements. Centrifugal blower impeller domain was considered as a rotating reference frame with a rotational speed of $880 \mathrm{rpm}$. The working fluid through the blower was air at $25^{\circ} \mathrm{C}\left(\rho=1.185 \mathrm{~kg} / \mathrm{m}^{3}\right)$.

\begin{tabular}{ll}
\hline Position & Boundary condition \\
\hline Inlet & Mass flow \\
Outlet & Static pressure $-0 \mathrm{~Pa}$ \\
Reference pressure & $101325 \mathrm{~Pa}(1 \mathrm{~atm})$ \\
Temperature & Air at $298^{\circ} \mathrm{K}$ \\
Walls & No slip wall \\
Impeller & Rotating reference frame \\
Casing & Stationary reference frame \\
Turbulence Model & k-epsilon \\
\hline
\end{tabular}

Table: 2 Boundary conditions [21-24]

Table. 2 shows boundary conditions used for analysis using Ansys 14.0 CFX.

\section{Result and discussion}

Using available experimental data, simulation was carried out in Ansys CFX.14 and compared with experimental. Total head and efficiency were computed which were compared with experimental data [21-24]. Boundary condition were used which indicated in Table.2

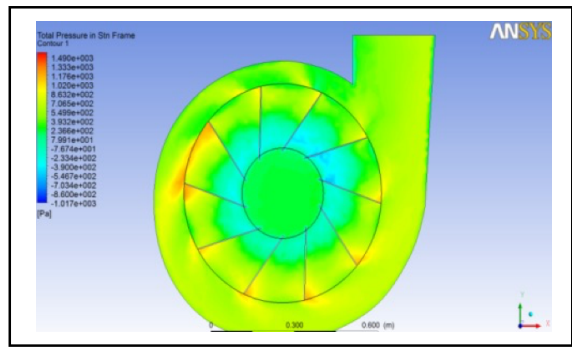

Figure: 2 Pressure contour for initial analysis

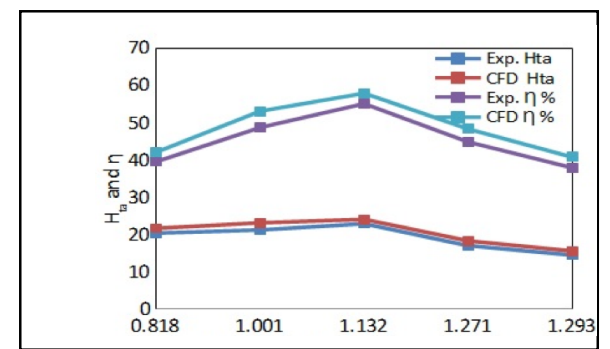

Figure: 3 Total head and efficiency versus flow rate

As shown in Figure: 2, initial investigation reveal relations of flow rate with total head and efficiency. As flow rate increases total head decrease because of energy conversion and good relation with experimental available data. Similarly, it was observed that as flow rate increases also increases but after 
certain value, efficiency starts decreases as flow rate increase. This is because blower has to work more for handling high flow rate. Comparison of computational and available experimental result were carried out as shown in Figure: 3. On the basis of above initial analysis, this paper represent the geometrical optimization of the blower using increasing the number of blades $[17,18]$ because Fig. 3 indicates that flow rate around $1.132 . \mathrm{m}^{3} / \mathrm{sec}$ is proven to be optimum and now this flow rate is taken as base. There are various geometrical parameters had been identified based on literature and above initial analysis as for examples like number of blades, blade thickness, rotational speed of blower, size of casing, gap between casing and impeller, impeller size, inlet blade angle, outlet blade angle etc. Out of this all, we had chosen number of blade, outlet angle and radial gap between impeller and volute casing for geometrical change, which can be optimized and best combination of these parameters can be found out which may be proven to give best head and efficiency. Table: 3 represent the used parameters and its variation which is used for computational analysis.

\begin{tabular}{llllll}
\hline Factors & Factor Name & Level 1 & Level 2 & Level 3 & Level 4 \\
\hline A & No. of Blades & 10 & 12 & 14 & 16 \\
B & Outlet angle & $76^{\circ}$ & $74^{\circ}$ & $72^{\circ}$ & $70^{\circ}$ \\
C & Radial gap & $\mathrm{R}$ & $\mathrm{R}+5$ & $\mathrm{R}+10$ & $\mathrm{R}+15$ \\
\hline
\end{tabular}

Table: 3 Parameters and its variations

$\mathrm{R}$ was original radial gap between impeller and casing $=70,100,120$ and $135 \mathrm{~mm}$ from inward to outward direction. This was considered as base radial gap. Now using design of experiment method (DoE), number of optimum experiment had been decided and simulation was carried out which was shown in Table 4.

\begin{tabular}{|c|c|c|c|c|c|c|c|}
\hline $\begin{array}{l}\text { Sr. } \\
\text { No. }\end{array}$ & Factor A & Factor B & Factor $\mathrm{C}$ & $\begin{array}{l}\text { Sr. } \\
\text { No. }\end{array}$ & Factor A & Factor B & Factor $\mathrm{C}$ \\
\hline 1 & 10 & $76^{\circ}$ & $\mathrm{R}$ & 9 & 14 & $76^{\circ}$ & $\mathrm{R}+10$ \\
\hline 2 & 10 & $74^{\circ}$ & $\mathrm{R}+5$ & 10 & 14 & $74^{\circ}$ & $\mathrm{R}+15$ \\
\hline 3 & 10 & $72^{\circ}$ & $\mathrm{R}+10$ & 11 & 14 & $72^{\circ}$ & $\mathrm{R}$ \\
\hline 4 & 10 & $70^{\circ}$ & $\mathrm{R}+15$ & 12 & 14 & $70^{\circ}$ & $\mathrm{R}+5$ \\
\hline 5 & 12 & $76^{\circ}$ & $\mathrm{R}+5$ & 13 & 16 & $76^{\circ}$ & $\mathrm{R}+15$ \\
\hline 6 & 12 & $74^{\circ}$ & $\mathrm{R}$ & 14 & 16 & $74^{\circ}$ & $\mathrm{R}+10$ \\
\hline 7 & 12 & $72^{\circ}$ & $\mathrm{R}+15$ & 15 & 16 & $72^{\circ}$ & $\mathrm{R}+5$ \\
\hline 8 & 12 & $70^{\circ}$ & $\mathrm{R}+10$ & 16 & 16 & $70^{\circ}$ & $\mathrm{R}$ \\
\hline
\end{tabular}

Table: 4 DoE Models for optimization of CF blower

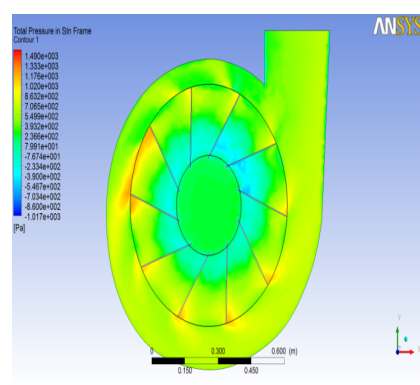

Model 1

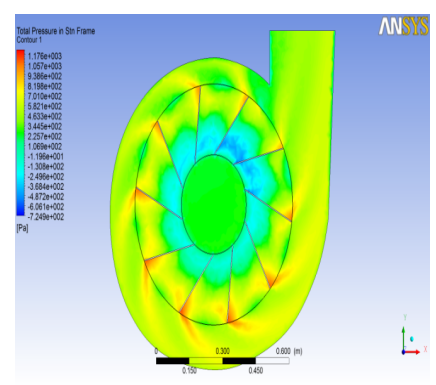

Model 2

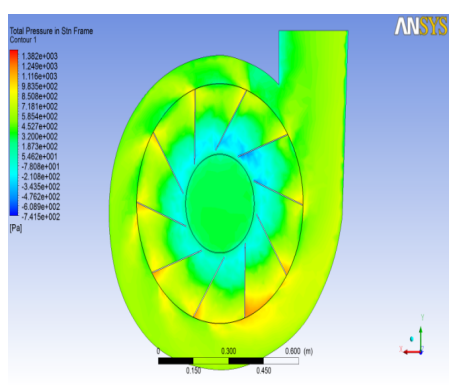

Model 3 


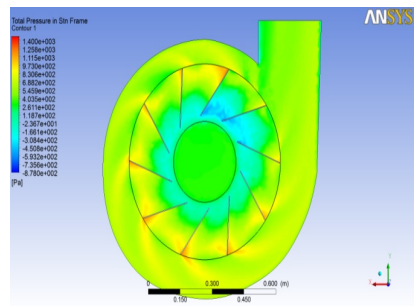

Model4

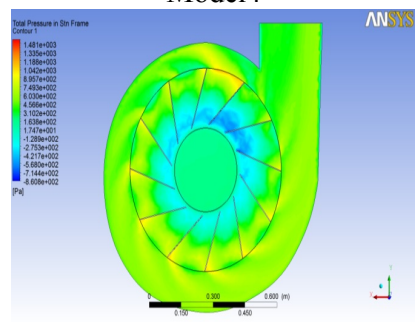

Model 7

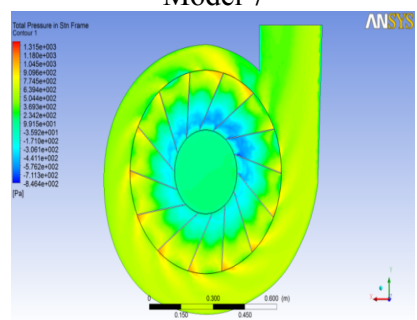

Model 10

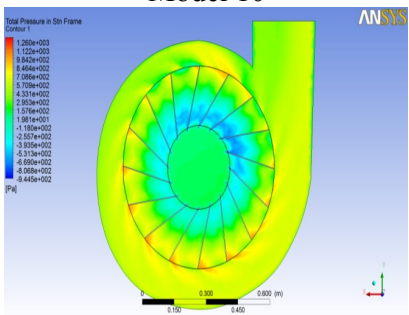

Model 13

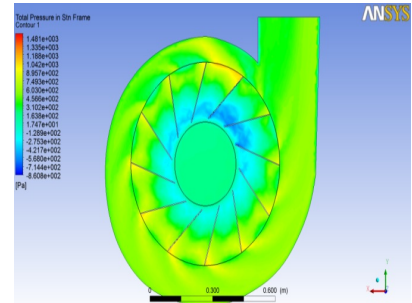

Model 5

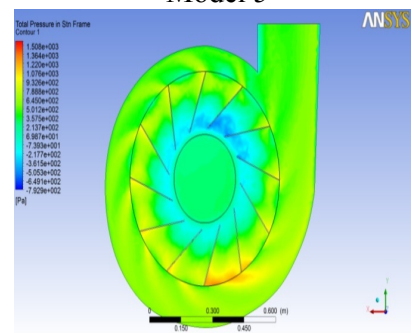

Model 8

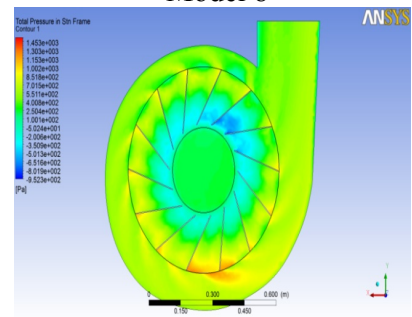

Model 11

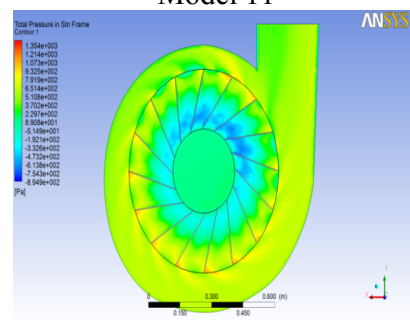

Model 14

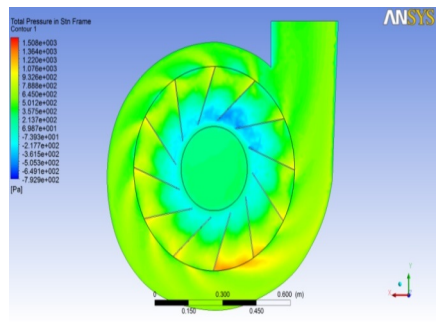

Model 6

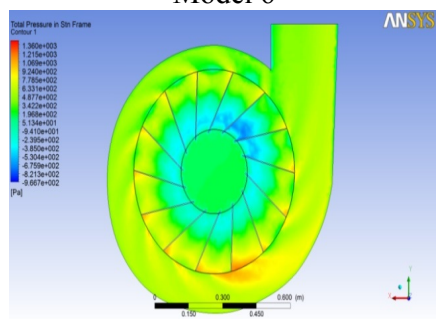

Model 9

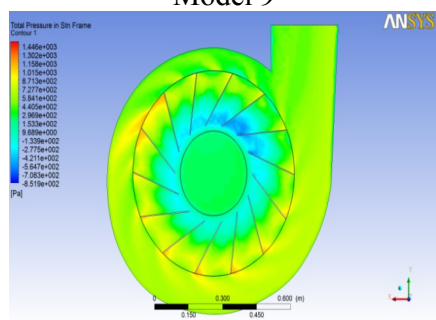

Model 12

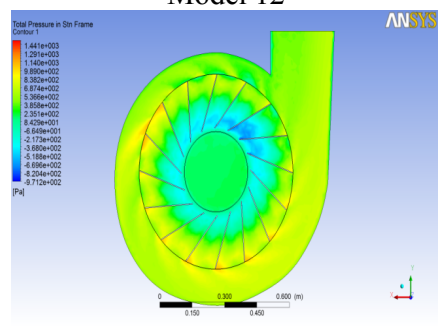

Model 15

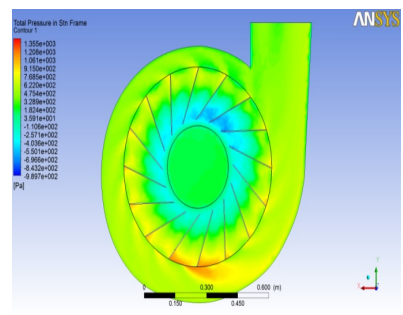

Model 16

Figure: 4 Ansys 14.0 CFD simulation images for all 16 models 
Figure: 4 represent pressure counters for all 16 DoE model, had revealed total head as output which was shown in Table.5. Using total output head, the calculations [20] of efficiency were made which was also indicated in Table 5.

\begin{tabular}{|c|c|c|c|c|c|}
\hline Model No & No. of Blades & Outlet angle & Radial gap (mm) & CFD Head ( $m$ of air) & CFD ๆo (\%) \\
\hline 1 & 10 & $76^{\circ}$ & $\mathrm{R}$ & 23.95 & 57.83 \\
\hline 2 & 10 & $74^{\circ}$ & $\mathrm{R}+5$ & 19.78 & 47.77 \\
\hline 3 & 10 & $72^{\circ}$ & $\mathrm{R}+10$ & 16.85 & 40.69 \\
\hline 4 & 10 & $70^{\circ}$ & $\mathrm{R}+15$ & 15.86 & 38.3 \\
\hline 5 & 12 & $76^{\circ}$ & $\mathrm{R}+5$ & 31.17 & 75.26 \\
\hline 6 & 12 & $74^{\circ}$ & $\mathrm{R}$ & 23.61 & 57.01 \\
\hline 7 & 12 & $72^{\circ}$ & $\mathrm{R}+15$ & 24.96 & 60.28 \\
\hline 8 & 12 & $70^{\circ}$ & $\mathrm{R}+10$ & 21.75 & 52.51 \\
\hline 9 & 14 & $76^{\circ}$ & $\mathrm{R}+10$ & 28.73 & 69.37 \\
\hline 10 & 14 & $74^{\circ}$ & $\mathrm{R}+15$ & 29.21 & 70.54 \\
\hline 11 & 14 & $72^{\circ}$ & $\mathrm{R}$ & 29.21 & 70.54 \\
\hline 12 & 14 & $70^{\circ}$ & $\mathrm{R}+5$ & 24.60 & 59.39 \\
\hline 13 & 16 & $76^{\circ}$ & $\mathrm{R}+15$ & 33.45 & 80.78 \\
\hline 14 & 16 & $74^{\circ}$ & $\mathrm{R}+10$ & 30.89 & 74.58 \\
\hline 15 & 16 & $72^{\circ}$ & $\mathrm{R}+5$ & 28.22 & 68.13 \\
\hline 16 & 16 & $70^{\circ}$ & $\mathrm{R}$ & 28.00 & 67.6 \\
\hline
\end{tabular}

Table: 5 Results obtained from CFD analysis of all DoE Models for optimization of CF blower

Figure: 4 represents computational fluid dynamics representation for understanding the variation of pressure head in impeller and radial gap between impeller and volute casing. From extraction of total pressure, pressure head and overall efficiency were calculated as shown in Table.5. From mathematical and computational analysis, it was found that Model 13 which was computed using 16 number of blades, with $76^{\circ}$ of blade outlet angle and $85 \mathrm{~mm}$ of radial gap was proven to be the most efficient out of all 16 models as it gives $33.45 \mathrm{~m}$ of air head as compared to 23.95 of our base model and $80.78 \%$ efficiency as compared to $57.83 \%$ which is around $23 \%$ higher as compared to our base model.

\section{Conclusions}

This paper shows comparative analysis of number of blades, blade outlet angle and radial gap between impeller and volute casing which are essential for design of centrifugal blower and analysis indicated that model 13 is the best parametric combination of number of blade, blade outlet angle and radial gap between impeller and casing for the given centrifugal blower. It gave $23 \%$ higher efficiency than experimental results using CFD analysis of centrifugal blower model.

\section{Acknowledgement}

I would like to thank Energy Process Equipment, Ahmedabad, for helping me for achieving this research work by giving experimental data. 


\section{References}

[1] Engin.T. (2006), "Study of tip clearance effects in centrifugal fans with unshrouded impellers using computational fluid dynamics", J.Power and Energy IMechE Vol.220, Part A, (pp. 599-610).

[2] Ng W.K. and Damodaran M., (2006), "Computational flow modelling for optimizing Industrial fan performance characteristics", European Conference on Computational Fluid Dynamics ECCOMAS CFD, the Netherlands.

[3] Karanth K.V. and Sharma N.Y, (2009), "CFD Analysis on the Effect of Radial Gap on Impeller-Diffuser Flow Interaction as well as on the Flow Characteristics of a Centrifugal Fan", IJRM, volume 2,( pp.1-8).

[4] Chen-Kang Huang,Mu-En Hsieh , (2009), "Performance analysis and optimized design of Backward curved airfoil centrifugal blower", HVAC \& R Research, Vol.15, No.3, (pp. 461-488).

[5] Singh O.P., Khilwani R., Sreenivasulu T., Kannan M., (2011), 'Parametric study of centrifugal fan performance: experiments \& numerical simulation ', IJAET, Vol.1, issue2, (pp. 33-50).

[6] Chunxi Li, Ling W.S., Yakui J., (2011), "The performance of a centrifugal fan with enlarged impeller", Energy Conversion and Management, Vol 52, Iss. 8-9 (pp .2902-2910).

[7] Gholamian M., Rao G.K.M., Bhramara P., (2011), "Effect of inlet on efficiency and flow pattern in centrifugal fan using CFD analysis and experimental validation", RARAME, ISBN: 987-1-61804-185-2, (pp.37-44).

[8] Vibhakar N., Masutage S.D., Channiwala S.A., (2012), "Three Dimensional CFD Analysis of Backward Curved Radial Tipped Blade Centrifugal Fan Designed as per Unified Methodology with Varying Number of Blades", IJETED, ISSN 2249-6149, Vol.1, Issue 2.

[9] Pathak Y.R., Baloni B.D., Channiwala Dr.S.A., (2012), "Numerical simulation of centrifugal blower using CFX”, IJECSCSE, ISSN: 2277-9477, (pp.242-247).

[10] Atre Pranav C., Thundil K.R.R., (2012), "Numerical design and parametric optimization of centrifugal fans with airfoil blade impellers", RJRS, ISSN: 2277-2502, Vol.1(10), (pp.7-10).

[11] Ragoth Singh R., Natraj M, (2012), "Optimizing impeller geometry for performance enhancement of a Centrifugal Blower using Taguchi Quality concept”, IJEST, ISSN: 0975-5462, Vol.4 No.10, (pp.43084314).

[12] Patel Keyur, Patel Prajesh, (2013), "Performance analysis and optimization of centrifugal fan", IJETED, ISSN 2249-6149, Vol.2, Issue 3, (pp.261-270).

[13] Krishna V., Kumar K.N., Kumar M.P., (2013), "Numerical Analysis of Centrifugal Blower Using CFD” IJERT), Vol. 2 Issue 8.

[14] Vivek Brahmbhatt, Gaurav Patel, (2014), "Performance Enhancement of IND 25 Centrifugal Fan by CFD Analysis", IJIRSET, Vol. 3, Issue 3, pp. (10743-10749)

[15] Jayapragasan C.N., Sai Phani Deep Kumar M., Dr. Janardhan Reddy K., (2014), "Redesign and Validation of an Industrial Blower", IJIRSET, ISSN: 2319-8753, Vol. 3, Issue 6, (pp.13999-14005)

[16] Wagh S., Panchagade D., (2014), "Analysing effect of impeller width on mass flow rate of centrifugal blower using CFD”, IJEAT, ISSN: 2249-8958, Vol.3, Issue 5,(pp.236-238)

[17] Jayapragasan C., Sumedh N., Suryawanshi J., Janardhan Reddy K., (2014), "Design optimization of Centrifugal fan of travelling cleaner", ARPN, ISSN: 1819-6608, Vol.9, No.9, (pp.1637-1644).

[18] Garrick O,P., (2015), "Theoretical model for predicting axial fans/blowers performance characteristics", IJMPE, ISSN: 2320-2092, Vol.3, Issue2, (pp.1-5)

[19]BUREAU OF ENERGY EFFICIENCY, BOOK-4: Energy Performance Assessment for Equipment and Utility Systems (pp. 87-97).

[20] Yunus A. Cengel, (2014), Fluid Mechanics, $2^{\text {nd }}$ edition , (pp.853-906).

[21] M.P.Engineering, Ahmedabad Company catalogue

[22] Fans \& Blower by LeapFrog Energy Technologies 2008 catalogue

[23] Electrical Energy Equipment: Fans and Blowers. UNEP. 2006. (p. 21).

[24] Tachnical Specification of CF Fan, M. P Engineering, February 2012 